\title{
Missing Test Results
}

National Cancer Institute

\section{Source}

National Cancer Institute. Missing Test Results. NCI Thesaurus. Code C95878.

Problem associated with the results of a test or measurement not appearing. 